The definitive version of this article is published by Blackwell and available online as:

Shigeto, S, Hubbard, L.J. and Dawson, P.J. On Farmland Prices and Rents in Japan. Agricultural Economics 2008, 39, 103-109.

http://www3.interscience.wiley.com/journal/119879532/abstract

\title{
On Farmland Prices and Rents in Japan
}

\author{
Sawako Shigeto \\ Tokyo University of Agriculture and Technology, Japan \\ L.J. Hubbard
}

School of Agriculture, Food and Rural Development, Newcastle University, UK P.J. Dawson

School of Agriculture, Food and Rural Development, Newcastle University, UK

Corresponding author:

\section{L.J. Hubbard}

Tel. +44 1912226886

Fax: +441912226720

lionel.hubbard@ncl.ac.uk

\begin{abstract}
Historically, the Japanese farmland market has been strongly regulated, although fundamental changes in policy were introduced in 1967 and 1980. This paper examines the relationship between farmland prices and rents in Japan for 1955-2000 using the cointegration procedure of Johansen et al. (2000) which admits structural breaks. Results show the presence of a cointegrating relationship with a significant break in 1980. There is Granger-causality from prices to rents, which suggests that
\end{abstract}


rents are determined within an institutional setting according to farmland prices. The rent-price elasticity is unity which supports the notion of efficiency in the farmland market.

\section{JEL Classification: C32, Q15, Q18}

Keywords: farmland market, Japan, cointegration, structural breaks

\section{Introduction}

Japan faces several major problems in terms of its farmland. First, average farm size is still less than 2 hectares, despite a number of policy measures over the past 40 years designed to foster larger holdings. Second, the area of abandoned farmland has been increasing, more than doubling between 1975 and 2000 (MAFF, 2000). Additionally, like many industrialised countries, Japan is under mounting international pressure to liberalise its farming sector and promote a more competitive agriculture. In all of these concerns, the farmland market has a key role.

Farmland issues in Japan have been addressed from the perspectives of a number of different disciplines - sociology, geography, engineering and economics due perhaps to the variety of what are perceived to be important contributory factors, e.g. family, terrain, irrigation and prices. From the economics perspective, there is a strong belief by some commentators that the theoretical models dominant in Europe and North America are inappropriate to the Japanese situation because, owing to government policy and the distinctive nature of Japanese farmers' behaviour, the land market is inefficient and distorted. Links between market inefficiency and the structural problems in Japanese agriculture are addressed by Honma (1994), Egaitsu and Shogenji (1995) and Kusakari (1998). Similarly, the importance of Japanese 
farmers' behaviour in holding on to land in the expectation of windfall profits from conversion to non-agricultural use is highlighted by Godo (1998, 2006 and 2007), who argues that farmland abandonment would not occur if policy and legislation were strictly enforced to deter such speculative possession.

The Present Valuation Model (PVM), based on Campbell and Shiller (1987 and 1988), which has been used widely in the study of the farmland market in Europe and North America (e.g., Burt, 1986; Featherstone and Baker, 1987; Lloyd et al., 1991; and Hallam et al., 1992), postulates that farmland prices are determined by rents. Although the PVM has strong theoretical appeal, empirical studies have often produced disappointing results. In response, some authors have included additional explanatory variables, e.g. transaction costs, risk and speculation. In spite of modifications to theory, empirical testing of the PVM remains inconclusive and Gutierrez et al. (2007) suggest that the problem may be deficiencies in the econometric methods employed. Whatever the correct specification of the PVM and the estimation method used, in the Japanese situation there is a more fundamental question regarding the direction of causality in the farmland price-rent relationship. In Japan, farm rents historically have been determined via a process of institutional governance and it is quite possible therefore that farmland price, rather than being determined by rent, is itself the determinant of rent. This is the issue we explore.

Japan has strict legislation limiting farmland conversion to non-agricultural use, although it is weakly enforced and there are many loopholes (Godo, 2007). In practice, farmland conversion, particularly for use in the public sector (e.g. roads and public facilities), is easily achieved even in those areas with special protection from 
non-agricultural demands. Egaitsu and Shogenji (1995), whilst arguing that falls in farmland prices in rural areas are the result of deteriorating agricultural profitability, acknowledge the influence of speculation on farmland markets which are close to the urban fringe. However, the speculative motive for explaining inefficiency in the Japanese farmland market may be exaggerated because such behaviour should only be present when and where opportunities exist (Ishii, 1991). Moreover, land price differentials between rural and urban fringe areas are not specific to Japan. Just and Miranowski (1993) find that land price expectations are the most important factor in determining land prices in the USA, but point out that these are themselves determined by yet other factors, including inflation and the opportunity cost of capital, as well as farm returns. Similarly, Goodwin et al. (2003) account explicitly for nonagricultural demands in the USA by including indicators of urban pressure (population, population growth and housing permits) in their model, which is estimated from farm-level data. While the speculative motive may reflect rational economic behaviour on the part of Japanese farmers, the more fundamental question remains as to whether a PVM-type approach is appropriate. That is, does rent determine land price in Japan?

We examine the relationship between farmland prices and rents in Japan empirically using a vector autoregressive (VAR) model which does not impose causality ex ante. This approach allows us to compare the PVM, where price is determined by rent, with what we term an 'institutional model' where rent is determined by price. The paper is structured as follows: Section 2 discusses farm rents and prices in Japan; Section 3 outlines the theory and empirical models; Section 4 reports the data and results; and Section 5 concludes. 


\section{Farm Rents and Prices in Japan}

The farmland market in Japan has been subject to a system of strict controls, although the situation has eased in more recent times following changes in social conditions and government policy. Land reform began immediately after the Second World War as a part of the transformation from feudalism to democracy. The main pillars of land reform were the reduction of rent and conversion of rent-in-kind to money rent, the creation of 'owner-cultivators', and the democratisation of the agricultural land committees (Koppel and Kim, 1993). Post-war, the main principle of farmland ownership was based strictly on owner-cultivators whose rights were protected under the Agricultural Land Law of 1952. Although interpreted more recently as 'cultivator-protection' (Sekiya, 2002), this principle restricted the ownership of land to individuals rather than business corporations, until 2000 , because of concerns regarding speculative possession. ${ }^{1}$

Under the 1952 law, the maximum level of farm rent was controlled, but in 1967 the policy was revised and direct rent control abolished in 1970. However, as a transitional measure, the control system was applied for a further 10 years to ongoing tenanted land, resulting in a marked increase in rent at the beginning of the 1980s. Following this policy change, the control system evolved into a 'standard system' which gave local Chambers of Agriculture a role in setting rents and advising on reductions in rents which were considered too high. Thus, after introduction of the

\footnotetext{
${ }^{1}$ However, Agricultural Production Corporations have been able to own farmland since 1962.
} 
standard system, the rent level was no longer controlled, but monitored by local agricultural committees (Sekiya, 2002). These committees still oversee rents and are able to exert influence in cases where the level may be regarded as high.

Although the farmland market in Japan has been strictly regulated through property right and rent determination, farmland prices have not been directly controlled. Instead, as in many developed countries, zoning has been applied to prevent speculative price movements arising from the demands of non-agricultural land use, especially in urban and urban-fringe areas. Counter to the New City Planning Law in 1968 which, inter alia, encompassed a large area of farmland, the Agricultural Land Use Promoting Law (1969) designated that 'farming areas' were not allowed to convert to non-agricultural use, barring exceptions. In return, farmers received various subsidies and tax incentives. Godo (1998 and 2007) is critical of the effectiveness of these regulations and argues that the farmland market, even in rural areas, is distorted because farmers rarely sell or lease land, and may even opt for land abandonment in the hope of future windfall gains from buy-outs by the public authorities who require land for non-agricultural use. Although the regulations prohibit land abandonment, in practice the penalties are ineffective.

Aggregated data of actual transaction prices for land are not available. The data we use in our empirical analysis are based on surveys undertaken by the Chambers of Agriculture to which all local transactions have to be reported. In the process of collection, the Chambers of Agriculture exclude from the data outliers which look odd in comparison to the local average. This partially allays fears that exceptionally high prices due to speculation may undermine our empirical analysis. 
The resulting dataset is the most consistent and longest time series of national land prices and rents available in Japan. The data relate to the average price $(1,000 \mathrm{yen} / \mathrm{are})$ and rent (yen/are) of 'good' paddy and 'good' vegetable fields (Japan Real Estate Institute). Real prices and rents are calculated using the GDP deflator.

From inspection of Japanese annual farmland prices and rents in real terms for 1955-2000 in Figure 1, there is a notable increase in rent around 1967 due to the revised maximum levels. Although direct control ended in 1970, a further marked increase in rent around 1980 highlights the policy change at the end of the transitionary period. Prices increased from the mid-1960s until 1984, but have since declined. This is most likely a result of falling profitability due to a chronic decrease in agricultural product prices (Egaitsu and Shogenji, 1995). The general pattern of prices appears similar to that of rents, but perhaps a better illustration of the relationship between the two is the rent/price ratio shown in Figure 2. Here, the impacts of the policy changes in 1967 and 1980 are more evident, particularly the latter.

\section{Figures 1 and 2 about here}

\section{Empirical Model of the Farmland Market}

When farmland prices reflect the productivity (or profitability) of land, the land market is efficient and price should equal the expected present value of future rents. This is the so-called PVM which, following inter alia Burt (1986), Featherstone and Baker (1987) and Falk (1991), can be represented as:

$$
\mathrm{P}_{\mathrm{t}}=\alpha \sum_{\mathrm{j}=1}^{\infty} \alpha^{\mathrm{j}} \mathrm{E}_{\mathrm{t}}\left[\mathrm{R}_{\mathrm{t}+\mathrm{j}}\right]
$$


where $P_{t}$ is the equilibrium farmland price at the beginning of time period $t ; R_{t}$ is the rent paid in period t, $\alpha$ is a constant discount factor equal to $1 /(1+i)$ where $i$ is the constant real discount rate and determined elsewhere, and $\mathrm{E}_{\mathrm{t}}$ is the conditional expectations operator based on information available at time t. Equation (1) implies a long-run relationship between the real price of farmland and its real return. Denote $\mathrm{P}^{*}$ and $\mathrm{R}^{*}$ as the long-run equilibrium price and a constant expectation of equilibrium return and (1) simplifies to:

$$
\mathrm{p}=\beta_{0}+\beta_{1} \mathrm{r}
$$

where $\mathrm{p}=\ln \mathrm{P}^{*}, \mathrm{r}=\ln \mathrm{R}^{*}, \beta_{1}=1$ and $\beta_{0}=\ln (1 / \mathrm{i})$ where $\ln$ is the natural logarithm. Following Lloyd (1994), we use the term 'market efficiency' to describe the restriction that $\beta_{1}=1$ in (2) where a $1 \%$ increase in rent leads to a $1 \%$ increase in price. The present value of a stream of rents in (1) and (2) may not be the only economic determinant of the price of land (see, for example, Just and Miranowski, 1993; and Goodwin, et al., 2003). Additionally, ownership may confer subjective satisfaction, as in Japan, where attachment to land often arises from a duty through sentiment to ancestors who acquired the land.

An alternative to the PVM in (2) stems from farm rents being determined by a process of institutional governance. Here, the direction of causality is reversed and the rent is set in accordance with the farmland price:

$$
\mathrm{r}=\beta_{0}^{\prime}+\beta_{1}^{\prime} \mathrm{p} .
$$

We denote (3) as the 'institutional model'. If $\beta_{1}=1$ in (2), then $\beta_{0}^{\prime}=\beta_{0}$ and $R=P . i$, that is, rent is set as a proportion, equal to a (constant) discount rate, of the farmland price. Alternatively, rent may be set in an ad hoc manner as a mark-down of the farmland price. This margin may vary between different economic environments under 
alternative policy regimes. Here, the discount rate plays no role in determining rent and there is no correspondence between (2) and (3).

The impact of policy changes in the Japanese farmland market differ between the PVM model in (2) and the ad hoc institutional model in (3). In (2), $\beta_{0}$ is constant since the real discount rate, $\mathrm{i}$, is constant. Accordingly, if the PVM is the true model, then farmland policy changes will not affect $\beta_{0}$. In contrast, if the institutional model in (3) is the true model, rent reform in 1967 and the cessation of rent control in 1980 may affect $\beta_{0}^{\prime}$, and $\beta_{1}^{\prime}$ is not constrained to be unity. ${ }^{2}$ We seek to test between these two alternatives.

To estimate (2) or (3) without imposing market efficiency, we use a vector autoregressive (VAR) model which does not assume the direction of causality ex ante:

$$
\mathrm{Y}_{\mathrm{t}}=\mu+\sum_{\mathrm{i}=1}^{\mathrm{k}} \mathrm{A}_{\mathrm{i}} \mathrm{Y}_{\mathrm{t}-\mathrm{i}}+\varepsilon_{\mathrm{t}}
$$

where $Y_{t}=\left[p_{t} r_{t}\right]^{\prime}, \mu$ and $A_{i}$ are matrices of parameters, $k$ is the lag length, and $\varepsilon_{t}$ are error terms. Falk (1991) and Hallam et al. (1992) inter alia note that many time series of farmland prices and rents are non-stationary and typically are integrated of order one, I(1). Here, ordinary least squares regressions are generally spurious and such series must be first-differenced to render them stationary, $\mathrm{I}(0)$. Where a linear combination of two I(1) series is stationary, they are cointegrated, the problem of spurious regression does not arise, and a meaningful long-run equilibrium exists (Granger, 1988). The standard test of Johansen (1988) for (non-)cointegration is based

\footnotetext{
${ }^{2}$ In the institutional model in (3), we also define 'market efficiency' where $\beta_{1}^{\prime}=1$.
} 
on the estimation of the VAR model in (4) transformed into its vector error-correction model (VECM) form. However, if structural breaks within the individual series occur, either at different times or at the same time and do not cancel each other out, cointegration must be analysed in a framework where breaks in the deterministic components are admitted. Johansen et al. (2000, equation 2.6) generalise the standard test by admitting up to two predetermined breaks and two models are considered, one with a broken level and one with a broken trend.

Denote $\mathrm{q}$ as the number of periods into which the sample is divided, and $\mathrm{j}$ as each period, so in the case of two breaks the sample is divided into three periods $(j=1, \ldots, q$ and $q=3$ ). Transforming (4) into its VECM form and generalising to admit breaks gives:

$$
\Delta \mathrm{Y}_{\mathrm{t}}=\alpha\left[\begin{array}{l}
\beta \\
\mu
\end{array}\right]^{\prime}\left[\begin{array}{c}
\mathrm{Y}_{\mathrm{t}-1} \\
\mathrm{t} \mathrm{E}_{\mathrm{t}}
\end{array}\right]+\gamma \mathrm{E}_{\mathrm{t}}+\sum_{\mathrm{i}=1}^{\mathrm{k}-1} \Gamma_{\mathrm{i}} \Delta \mathrm{Y}_{\mathrm{t}-\mathrm{i}}+\sum_{\mathrm{j}=2}^{\mathrm{q}} \kappa_{\mathrm{j}} \mathrm{D}_{\mathrm{j}, \mathrm{t}-1}+\sum_{\mathrm{m}=1}^{\mathrm{d}} \Theta_{\mathrm{m}} \mathrm{w}_{\mathrm{m}, \mathrm{t}}+\varepsilon_{\mathrm{t}}
$$

where $\Delta$ is the difference operator; $\mathrm{E}_{\mathrm{t}}=\left[\begin{array}{lllll}\mathrm{E}_{1 \mathrm{t}} & \mathrm{E}_{2 \mathrm{t}} & \ldots & \mathrm{E}_{\mathrm{q}}\end{array}\right]^{\prime}$ is a vector of $\mathrm{q}$ dummy variables with $E_{j, t}=1(j=1, \ldots, q)$ if observation $t$ belongs to the $j^{\text {th }}$ period and zero otherwise, and the first k observations are set to zero. Following Dennis (2006, p.27), impulse dummy variables, $D_{j, t-1}(j=2, \ldots, q)$, equal unity if observation $t$ is the first observation of the $\mathrm{j}^{\text {th }}$ period and are included to render the corresponding residuals zero thereby allowing the conditional likelihood function to be derived given the initial values in each period. Intervention dummies, $\mathrm{w}_{\mathrm{m}, \mathrm{t}}(\mathrm{m}=1, \ldots, \mathrm{d})$, are also included to render the residuals well-behaved following inter alia Hendry and Mizon (1993). The short-run parameters are $\gamma$ of $\operatorname{order}(2 \times \mathrm{q}), \Gamma_{\mathrm{i}}(\mathrm{i}=1, \ldots, \mathrm{k}-1)$ of order $(2 \times 2), \kappa_{\mathrm{j}}$ $(j=2, \ldots, q)$ of order $(2 \times 1)$, and $\Theta_{m}(m=1, \ldots, d)$ of order $(2 \times 1)$. The innovations, $\varepsilon_{t}$, are assumed to be iid with mean zero and symmetric and positive definite variance. The 
long-run drift parameters are $\mu=\left[\mu_{1} \mu_{2} \ldots \mu_{\mathrm{q}}\right], \alpha$ is a vector of adjustment parameters, and $\beta$ are the long-run coefficients in the cointegration vector. The cointegration hypothesis is formulated by testing the $\operatorname{rank}(\mathrm{r})$ of $\pi=\alpha\left[\begin{array}{l}\beta \\ \mu\end{array}\right]^{\prime}$ and its asymptotic distribution depends on the number of non-stationary relations, the location of breakpoints, and trend specification.

Johansen et al. (2000) examine two models in (2). Model 1 is where there are no linear trends in the levels of the endogenous I(1) variables and the first-differenced series have a zero mean; here the broken level is restricted to the cointegration space. Model 2 is where any long-run linear growth is not accounted for by the model and a broken linear trend is present in the cointegration vectors. To test between the models, the Pantula principle (Harris and Sollis, 2003, pp.134-135) is used to test the joint hypothesis of both rank and deterministic components (Johansen, 1992).

Given the cointegration rank, further restrictions on the cointegration space can be tested using log-likelihood ratios (LR). Harris and Sollis (2003, pp.142-152) consider these tests in the standard framework but they can be extended here. Assume

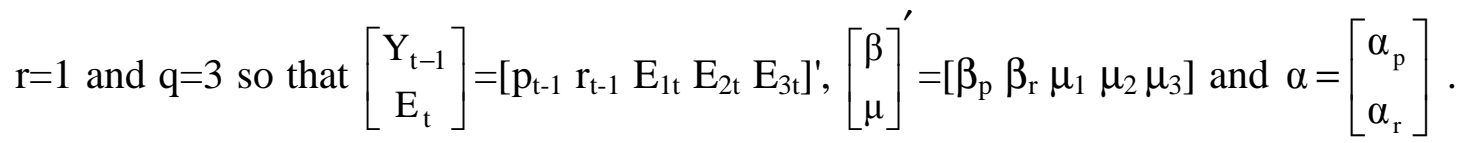

First, we check for unit roots, testing whether each series is stationary around a broken level or trend. The hypothesis of trend stationarity of $p_{t}$ for example is:

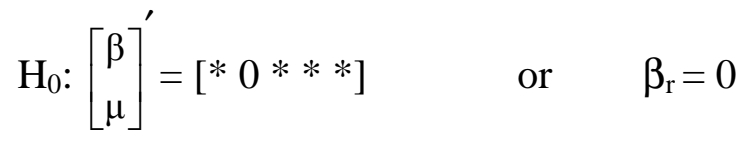

where asterisks $(*)$ denote unrestricted parameters, and $\operatorname{LR} \sim \chi_{1}^{2}$. Second, we test 
market efficiency, i.e. the null that $\beta_{1}=1$ in the PVM in (2) or that $\beta_{1}^{\prime}=1$ in the institutional model in (3):

$$
\mathrm{H}_{0}:\left[\begin{array}{l}
\beta \\
\mu
\end{array}\right]^{\prime}=[1-1 * * *] \quad \text { or } \quad \beta_{\mathrm{p}}=-\beta_{\mathrm{r}}
$$

and $\mathrm{LR} \sim \chi_{1}^{2}$.Third, we test whether the structural breaks are statistically significant. Testing the first break for example, the null is that the intercepts or trends are equal in the first and second periods, that is:

$$
\mathrm{H}_{0}:\left[\begin{array}{l}
\beta \\
\mu
\end{array}\right]^{\prime}=\left[\begin{array}{llll}
* * & 1 & 1 & *
\end{array}\right] \quad \text { or } \quad \mu_{1}=\mu_{2}
$$

and LR $\sim \chi_{1}^{2}$. Finally, we examine weak exogeneity. To test for the weak exogeneity of $\mathrm{p}_{\mathrm{t}}$ for example, the null is:

$$
\mathrm{H}_{0}: \alpha_{\mathrm{p}}=0
$$

and LR $\sim \chi_{1}^{2}$. If the tests imply that $\alpha_{\mathrm{p}}=0$ and $\alpha_{\mathrm{r}} \neq 0$, price Granger-causes rent, and vice versa; and if $\alpha_{p} \neq 0$ and $\alpha_{r} \neq 0$, there is bi-directional causality or feedback between prices and rents.

\section{Results}

Using Models 1 and 2 implicit in (5), we test for cointegration between $\mathrm{p}_{\mathrm{t}}$ and $\mathrm{r}_{\mathrm{t}}$ following Johansen et al. (2000) allowing for breaks in 1967 (with the second period starting in 1968) and 1980 (with the third period starting in 1981). ${ }^{3,4}$ To model

${ }^{3}$ Estimation was carried-out in CATS, Version 2 (Dennis, 2006).

${ }^{4}$ An alternative model was also estimated which included the real discount rate. Results were similar to Lloyd et al. (1991), namely that the real discount rate has no significant effect on the rent-farmland price nexus. 
the dynamics of the system, the number of lags $(\mathrm{k})$ in each model is chosen according the Hannan-Quinn criterion, and $\mathrm{k}=4$. We now test for both deterministic components in (5) and for cointegration using trace statistics following the Pantula principle, and the results are shown in Table 1. One cointegration vector is found (r=1) and Model 1 is preferred. Thus there is a unique long-run relationship between $\mathrm{p}_{\mathrm{t}}$ and $\mathrm{r}_{\mathrm{t}}{ }^{5}$ Residual mis-specification tests suggest that the residuals are non-normal. Accordingly, Model 1 is re-estimated with the inclusion of intervention dummies, $w_{m, t}$ in (5) for 1973 and 1982 where residuals are at least twice the standard deviation of all residuals in each error-correction equation. The trace statistics for this modified model are shown in Table 1 and the residuals are now well-behaved. ${ }^{6}$

\section{Table 1 about here}

${ }^{5}$ The corresponding results where no breaks are admitted following Johanson (1988) show no evidence of cointegration between prices and rents. For Model 1, the Hannan-Quinn criterion indicates $\mathrm{k}=2$ and the trace statistic for testing the null that $\mathrm{r}=0$ is 10.53 [p-value: 0.59], and 1.84 [0.80] when testing $\mathrm{r}=1$. For Model 2 and again for $\mathrm{k}=2$, the trace statistic for testing the null that $\mathrm{r}=0$ is 12.08 [0.80], and $3.27[0.83]$ when testing $r=1$. This suggests that the modelling of breaks in cointegration analyses is important.

${ }^{6}$ Residual multivariate mis-specification statistics (Dennis, 2006, pp.176-180) are: the Doornik and Hansen (1994) test for normality is 8.52 [p-value: 0.07]; the LM-test for second-order autocorrelation is 3.76 [0.44]; and the LM-test for ARCH of order two is 8.84 [0.96]. 
Table 2 shows results of the hypothesis tests for Model 1. First, the nulls of stationarity of $p_{t}$ and $r_{t}$ in (6) are rejected: both series are $I(1)$, and stationarity implied by the cointegrating vector does not come from the stationarity around a broken level of one series but from a linear combination of both. Second, the null of market efficiency, that $\beta_{\mathrm{p}}=-\beta_{\mathrm{r}}$ in (7), i.e. $\beta_{1}=1$ in (2) or $\beta_{1}^{\prime}=1$ in (3), is not rejected. Thus, the elasticity between prices and rents is unity and the farmland market in Japan is efficient. Third, we test for the existence of breaks in the long-run equilibrium as in (8): the null that $\mu_{1}=\mu_{2}$ is not rejected while the null that $\mu_{2}=\mu_{3}$ is rejected. Thus, the break in 1980 is statistically significant and impacts on the long-run link between prices and rent. In contrast, the hypothesised break in 1967 is insignificant. Fourth, tests for weak exogeneity, as in (9), reveal the null that $\alpha_{p}=0$ is not rejected while the null that $\alpha_{r}=0$ is rejected. Thus, price is weakly exogenous which implies that rent is Granger-caused by prices and the institutional model in (3) is preferred. The estimate of the significant adjustment speed coefficient is $\alpha_{\mathrm{r}}=0.379$ which implies that $38 \%$ of any disequilibrium is removed each year by adjustments in $r_{t}$, with $90 \%$ being removed within five years and $99 \%$ within 10 years. Adjustment therefore appears to be quite fast.

\section{Table 2 about here}

The cointegrating vector is now normalised on $r_{t}$ (since $p_{t}$ is weakly exogenous) and the restrictions above, namely that $\beta_{\mathrm{p}}=-\beta_{\mathrm{r}}, \mu_{1}=\mu_{2}$ and $\alpha_{\mathrm{p}}=0$, are imposed:

$$
r_{t}=p_{t}+2.572 E_{1 t}+2.572 E_{2 t}+2.766 E_{3 t}+z_{t} .
$$

Equation (10) provides two insights. First, only the structural break in 1980 had a 
permanent effect on the link between rents and farmland prices. Rent was set at $13 \%^{7}$ of farmland price before 1980 and at $16 \%$ thereafter. Thus the break in 1980 resulted in an increase of $21 \%$ in the rent/price ratio. Second, since the cointegrating relationship in (10) is identified, non-rejection of the null that $\beta_{1}^{\prime}=1$ in the preferred institutional model in (3) implies that the long-run rent elasticity with respect to the farmland price is unity and a $1 \%$ increase in price causes a $1 \%$ increase in rents.

\section{Concluding Remarks}

Japan faces several problems in terms of its agricultural land: small-scale farms, a marked increase in land abandonment, and international pressure to become more competitive in farming. Economic theory postulates that the market mechanism should achieve an efficient allocation of farmland, but there is a belief in Japan that this market is distorted due to government intervention through regulations on property rights, direct and indirect control of rents, and restrictions on the conversion of farmland to non-agricultural uses. In assessing efficiency in the farmland market, we have analysed the long-run relationship between price and rent and tested between the conventional PVM and an alternative 'institutional model' where the direction of causality is reversed.

Using the procedure of Johansen et al. (2000) and data for 1955-2000, we tested for cointegration between farmland prices and rents, allowing for structural breaks which coincide with policy changes in 1967 and 1980. Results suggest that rents are Granger-caused by farmland prices. The break in 1980 is statistically

\footnotetext{
${ }^{7} \mathrm{R} / \mathrm{P}=e^{2.572}=0.13$
} 
significant and causes a rise of $21 \%$ in the rent/price ratio. The break in 1967 is insignificant. The hypothesis of unit elasticity cannot be rejected and a $1 \%$ increase in farmland price leads to a $1 \%$ increase in rents. Results further imply that $38 \%$ of any disequilibrium is removed each year by adjustments in rent, with $90 \%$ being removed within five years and $99 \%$ within 10 years.

The result that rents are Granger-caused by farmland prices is the opposite of what one would expect under the PVM. There are three possible reasons for this. First, the theory embodied in the PVM or its specification may be incorrect or incomplete, as suggested by the literature that has attempted to modify the price-rent relationship (e.g., Just and Miranowski, 1993). Second, the econometric methods employed may be inadequate (Gutierrez et al., 2007). Third, and perhaps of most interest in the present case, is that whilst the PVM may be appropriate for Europe and North America, it is inappropriate for the Japanese situation. This is the possibility we have explored and that our results support, but there are three caveats. First, the sample comprises 46 observations and it is well-known that tests for cointegration and causality have poor size and power properties when applied to individual time series of moderate length. Additionally, although we believe our data to be the most appropriate available, they may not represent a sufficiently accurate measure of the rents and prices actually paid in farmland transactions. Second, we hypothesise either that farmland prices are caused by rents or that rents are caused by farmland prices. We do not examine whether the causality is from price to rent before rent reform and the opposite thereafter, since very small sample sizes would lower size and power properties of statistical tests further. Third, if the PVM is the true model, there is a tension with its empirical counterpart: the theoretical PVM posits a constant that is a 
function of the discount rate, while our empirical model allows for the constant to vary between policy regimes. However, it appears that the discount rate has no significant effect on the rent-price relationship; the constant is significantly different between regimes, and prices Granger-cause rents.

In conclusion, we are inclined to concur with the view that the PVM is not an appropriate description of the operation of the Japanese farmland market. It appears more likely that rents are determined within an institutional setting, and we prefer therefore to opt for our institutional model where rents are set as a 'mark-down' on farmland prices. Nevertheless, our results suggest that the Japanese farmland market is efficient, which is counter to the ideas of some commentators, and that the fundamental policy revision in 1980 had a permanent impact on the structure of the farmland market.

\section{References}

Burt, O.R., 1986. Econometric modeling of the capitalization formula for farmland prices, Am. J. Agric. Econ. 68, 10-26.

Campbell, J., Shiller, R., 1987. Cointegration and tests of present value models, J. Political Econ. 95, 1062-1088.

Campbell, J., Shiller, R., 1988. The dividend-price ratio and expectations of future dividends and discount factors, Rev. Fin. Stud. 1, 195-228.

Dennis J.G., 2006. CATS in RATS, Version 2.Evanston, IL: Estima.

Doornik, J.A., Hansen, H., 1994. An Omnibus Test for Univariate and Multivariate Normality. Oxford: Nuffield College. 
Egaitsu, N., Shogenji, S., 1995. A New Proposal for Enrichment of Japan's Agricultural Industry, Ieno Hikari Association. (in Japanese)

Falk, B., 1991. Formally Testing the Present Value Model of Farmland Prices, Am. J. Agric. Econ. 73, 1-10.

Featherstone, A.M., Baker, T.G., 1987. An Examination of Farm Sector Real Asset Dynamics: 1910-85, Am. J. Agric. Econ. 69, 532-546.

Godo, Y., 1998. Agricultural Land Issues and Japanese Agriculture in M. Okuno and M. Honma, eds., Economic Analysis of Agricultural Problems. Japan: Nihon Keizai Shimbun, Inc. 61-86. (in Japanese).

Godo, Y., 2006. Food and Agriculture in Japan, NTT Publishing Co., Ltd. Tokyo (in Japanese)

Godo, Y., 2007. The Puzzle of Small Farming in Japan, Asia Pacific Economic Papers 365, Canberra: Australia-Japan Research Centre.

Goodwin, B.K., Mishra, A.K., Ortalo-Magné, F.N., 2003. What's wrong with our models of agricultural land values? Am. J. Agric. Econ., 85, 744-752.

Granger, C.W.J., 1988. Some recent developments in a concept of causality, $J$. Econometrics, 39, 199-211.

Gutierrez, L., Westerlund, J., Erickson, K., 2007. Farmland prices, structural breaks and panel data, European Rev. Agric. Econ., 34, 161-179.

Hallam, D., Machado, F., Rapsomanikis, G., 1992. Co-integration analysis and the determinants of land prices, J. Agric. Econ, 43, 28-37.

Harris, R., Sollis, R., 2003. Applied Time Series Modelling and Forecasting. Chichester: John Wiley and Sons Ltd.

Hendry, D.F., Mizon, G..E., 1993. Evaluating Dynamic Econometric Models by Encompassing the VAR. in P.C.P. Phillips, eds., Models, Methods and 
Applications of Econometrics. Oxford: Basil Blackwell, 272-300.

Honma, M., 1994. Political Economy of Agricultural Problems, Japan: Nihon Keizai Shimbun, Inc. (in Japanese).

Ishii, H., 1991. Various Issues Related to Agricultural Land Prices and Cash Rent, in N. Imamura and K. Kawai, eds., National Land Use and Agricultural Land Issues. Tokyo: Rural Culture Association, 147-203 (in Japanese)

Japan Real Estate Institute. The Survey on Land Prices and Farm Rents. Japan.

Johansen, S., 1988. Statistical analysis of cointegrating vectors, J. Econ. Dynamics and Control, 12, 231-254.

Johansen, S., 1992. Determination of cointegration rank in the presence of a linear trend, Ox. Bull. Econ. and Stats., 54, 383-397.

Johansen, S., Mosconi, R., Nielsen, B., 2000. Cointegration analysis in the presence of structural breaks in the deterministic trend, Econometrics J., 3, 216-249.

Just, R.E., Miranowski, J.A., 1993. Understanding Farmland Price Changes. Am. J. Agric. Econ., 75, 156-168.

Koppel, B., Kim, D.Y., 1993. Land Policy Problems in East Asia - Toward New Choices - A Comparative Study of Japan, Korea and Taiwan, East-West Centre.

Kusakari, H., 1998. Japanese Rice Farming and the Development of Rice Policy. in M. Okuno and M. Honma, eds., Economic Analysis of Agricultural Problems. Japan: Nihon Keizai Shimbun. 115-141 (in Japanese).

Lloyd, T.A., 1994. Testing a present value model of agricultural land values, Ox. Bull. Econ. and Stats., 56, 209-223.

Lloyd, T.A., Rayner, A.J., Orme, C.D., 1991. Present value models of agricultural land prices in England and Wales, European Rev. Agric. Econ., 18, 141-166. 
MAFF, 2000. Survey on Farm Management Trend. Japan.

Sekiya, S., 2002. Japanese Land System. Tokyo: Japan: Agriculture Policy Research Association (in Japanese). 
Table 1: Cointegration Tests (Trace Statistics)

\begin{tabular}{lrcc}
\hline $\mathrm{H}_{0}\left(\mathrm{H}_{1}\right)$ & Model 1 & Model 2 & $\begin{array}{c}\text { Model 1 } \\
\text { with intervention dummies }\left(\mathrm{w}_{\mathrm{m}, \mathrm{t}}\right)\end{array}$ \\
\hline $\mathrm{r}=0(\mathrm{r} \geq 1)$ & $44.94[0.00]$ & $93.00[0.00]$ & $48.59[0.00]$ \\
$\mathrm{r}=1(\mathrm{r} \geq 2)$ & $9.62[0.39]^{*}$ & $10.33[0.32]$ & $9.98[0.35]$ \\
\hline
\end{tabular}

Notes:

1. p-values in brackets.

2. * denotes the first time that the null is not rejected in Models 1 and 2 without intervention dummies $\left(\mathrm{w}_{\mathrm{m}, \mathrm{t}}\right)$ using the Pantula principle.

3. Intervention dummies $\left(\mathrm{w}_{\mathrm{m}, \mathrm{t}}\right)$ are included for: 1973 and 1982. 
Table 2: Hypothesis Tests

\begin{tabular}{llcr}
\hline Null Hypothesis & & $\mathrm{H}_{0}$ & LR-Statistic \\
\hline Stationarity of: & $\mathrm{p}_{\mathrm{t}}$ & $\beta_{\mathrm{r}}=0$ & $16.86[0.00]$ \\
& $\mathrm{r}_{\mathrm{t}}$ & $\beta_{\mathrm{p}}=0$ & $9.86[0.00]$ \\
Market efficiency & & $\beta_{\mathrm{p}}=-\beta_{\mathrm{r}}$ & $0.51[0.47]$ \\
Break: & 1967 & $\mu_{1}=\mu_{2}$ & $1.49[0.22]$ \\
& 1980 & $\mu_{2}=\mu_{3}$ & $4.15[0.04]$ \\
Weak exogeneity of: & $\mathrm{p}_{\mathrm{t}}$ & $\alpha_{\mathrm{p}}=0$ & $3.39[0.07]$ \\
& $\mathrm{r}_{\mathrm{t}}$ & $\alpha_{\mathrm{r}}=0$ & $27.61[0.00]$ \\
\hline
\end{tabular}

Note: p-values in brackets. 
Figure 1: Land Prices and Rents : 1955-2000

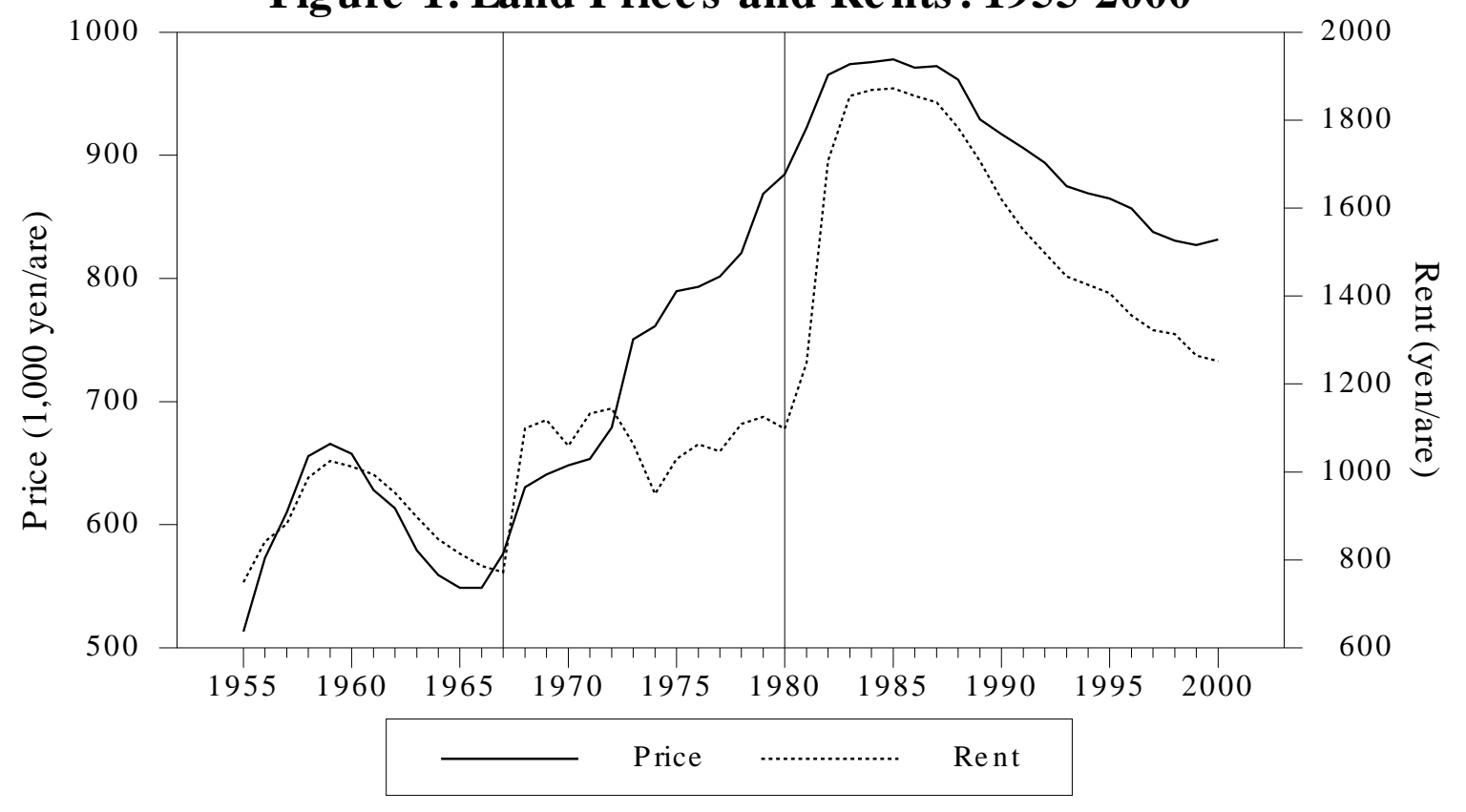


Figure 2: Rent/Price Ratio: 1955-2000

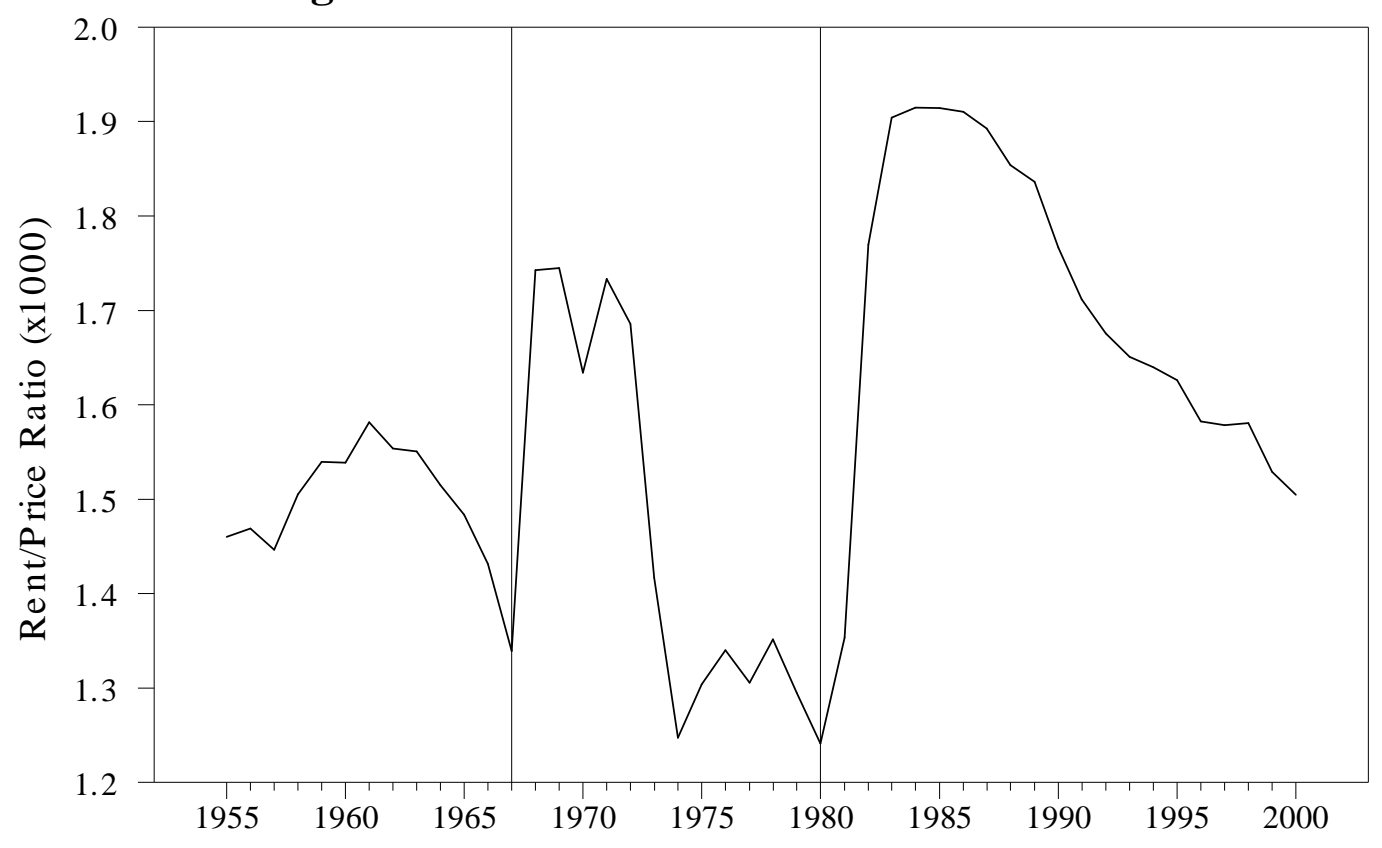

